\title{
Article
}

\section{The Impact of Illegal Waste Sites on the Transmission of Zoonotic Cutaneous Leishmaniasis in Central Tunisia}

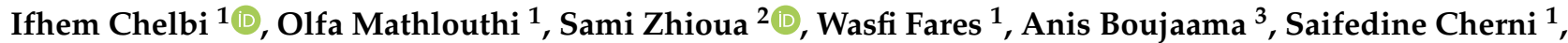 \\ Walid Barhoumi ${ }^{1}$, Khalil Dachraoui ${ }^{1}$, Mohamed Derbali ${ }^{1}$, Mohamed Abbass ${ }^{1}$ and Elyes Zhioua ${ }^{1, *}$
}

1 Laboratory of Vector Ecology, Pasteur Institute of Tunis, 1002 Tunis, Tunisia; ifhemc2001@yahoo.fr (I.C.); olfa85mathlouthi@yahoo.fr (O.M.); fwasfi@yahoo.fr (W.F.); saifcherni@yahoo.com (S.C.); walidbarhoumi.ipt2009@yahoo.fr (W.B.); khalil.dachraoui@yahoo.com (K.D.); derbali.hiba@gmail.com (M.D.); m.abbas9900@gmail.com (M.A.)

2 Laboratory of Biostatistics, Pasteur Institute of Tunis, 1002 Tunis, Tunisia; sami.zhioua2@gmail.com

3 National Institute of Statistics, 1002 Tunis, Tunisia; anis.boujaama@gmail.com

* Correspondence: elyes.zhioua@gmail.com; Tel.: +216-70-945-577; Fax: +216-70-944-222

check for

updates

Citation: Chelbi, I.; Mathlouthi, O.; Zhioua, S.; Fares, W.; Boujaama, A.; Cherni, S.; Barhoumi, W.; Dachraoui, K.; Derbali, M.; Abbass, M.; Zhioua, E. et al. The Impact of Illegal Waste Sites on the Transmission of Zoonotic Cutaneous Leishmaniasis in Central Tunisia. Int. J. Environ. Res. Public Health 2021, 18, 66. https:/ /dx. doi.org/10.3390/ijerph18010066

Received: 12 October 2020

Accepted: 17 November 2020

Published: 24 December 2020

Publisher's Note: MDPI stays neutral with regard to jurisdictional claims in published maps and institutional affiliations.

Copyright: (C) 2020 by the authors. Licensee MDPI, Basel, Switzerland. This article is an open access article distributed under the terms and conditions of the Creative Commons Attribution (CC BY) license (https: / / creativecommons.org/ licenses/by/4.0/).

\begin{abstract}
Illegal waste disposal represents a risk health factor for vector-borne diseases by providing shelter for rodents and their ectoparasites. The presence of the Phlebotomus papatasi vector of Leishmania major, an etiologic agent of zoonotic cutaneous leishmaniasis (ZCL), was assessed at illegal waste sites located at the vicinity of villages in endemic areas of Central Tunisia. The study was performed over a two-year period over three nights from July to September 2017, and over three nights in September 2018. Household waste is deposited illegally forming dumpsites at the vicinity of each village and contains several rodent burrows of Psammomys obesus, the main reservoir host of L. major. Sandflies were collected from rodent burrows in the natural environment and in dumpsites using sticky traps and were identified at species level. Female sandflies were tested for the presence of L. major by PCR. Our entomological survey showed that Phlebotomus papatasi is the most abundant sandfly species associated with rodent burrows in these waste sites. The densities of $P$. papatasi in dumpsites are significantly higher compared to the natural environment. The minimum infection rate of P. papatasi with L. major in these illegal waste sites is not significantly different compared to the natural environment. Considering the short flight range of $P$. papatasi, increases in its densities, associated with burrows of $P$. obesus in illegal waste sites located at the edge of villages, expands the overlap of infected ZCL vectors with communities. Thus, illegal waste sites pose a high risk of spreading ZCL to neighboring home ranges. Waste management is an environmentally friendly method of controlling sandfly populations and should be included in an integrated management program for controlling ZCL in endemic countries.
\end{abstract}

Keywords: illegal waste sites; sandflies; rodents; leishmaniasis; waste management

\section{Introduction}

Zoonotic cutaneous leishmaniasis (ZCL) is a neglected tropical disease that affects thousands of people annually in the endemic areas of Central and Southern Tunisia [1,2]. This disease is caused by the parasite Leishmania major, and is transmitted by the sandfly Phlebotomus papatasi [3,4]. In this region, the fat sand rat, Psammomys obesus, and the desert jird Meriones shawi, are the principal reservoir hosts of L. major [5-10]. Although ZCL is generally not fatal, the lesions produced may cause substantial disfigurement and severe distress to infected individuals with lifelong psychological and social consequences [11]. There is no ZCL vaccine available and treatment is based on chemotherapy. In addition, programs concerning vector and reservoir host control are currently absent for the prevention of this neglected tropical disease.

Following the construction of the dam of Sidi Saad in Central Tunisia and the resettlement of non-immune human populations, a major outbreak of ZCL occurred in 
1982-1983 [12]. A total of 15,897 ZCL cases were reported from 1999 to 2004 with an average annual incidence rate of 669.7 per 100,000 inhabitants in the governorate of Sidi Bouzid [13]. About $63.4 \%$ of the cases were from rural areas, which account for $71 \%$ of the total population of the governorate of Sidi Bouzid (395,506 inhabitants).

Rural areas located in Central Tunisia are characterized by poor housing conditions and unsuitable waste management, where villages are surrounded by chenopod fields that consist of salt flats of halophytic vegetation, predominantly populated by plants of the family Chenopodiaceae: Salsola tetrandra, Suaeda fruticosa, and Arthrocnemum glaucum. These salt flats are used also as grazing areas for livestock [14].

These chenopod fields are also the natural habitats of $P$. obesus, the main reservoir host of L. major [14]. In the absence of total waste management, household waste made of materials such as rubber, plastic, animal dung, and earthen and organic matter is deposited at the vicinity of villages, creating dumpsites. Illegal waste is deposited on the outskirts of villages and can sustain populations of P. obesus [15]. As a general assumption, adult sandflies in villages come from breeding and resting sites located on the surrounding land [16]. We hypothesized that illegal waste sites deposited at the edge of villages impact the breeding of P. papatasi and subsequently increase the transmission risk of ZCL.

\section{Materials and Methods}

The study was performed in the villages of Hichria $\left(34^{\circ} 50^{\prime} \mathrm{N}, 9^{\circ} 28^{\prime} \mathrm{E}\right)$ and Ouled Mohamed ( $\left.34^{\circ} 53^{\prime} \mathrm{N}, 9^{\circ} 35^{\prime} \mathrm{E}\right)$, located in the governorate of Sidi Bouzid (Figure 1), a highly endemic area with multiple foci of ZCL [1,13]. Hichria and Ouled Mohamed are $15 \mathrm{~km}$ away from one another and belong to the delegation of Souk Jedid.

Both villages are surrounded by non-agricultural fields made of chenopods (Figure 2), which are the natural habitat of P. obesus (Figure 3). Household waste is deposited illegally, forming dumpsites at the outskirts of each village and containing several burrows of P. obesus [15] (Figure 4). Thus, around each village, a natural site adjacent to a waste disposal site is considered in this study.

Both dumpsites made of household waste and chenopod fields surrounding the villages sustain sand rat colonies [15]. In Tunisia, the phenology of P. papatasi is characterized by two main peaks of activity: one in June-July and a second, larger peak in SeptemberOctober [1]. The collection of sandflies was performed in 2017 over three nights (1 night in July and 2 nights in September). The same entomological survey was performed over three nights in September 2018.

Sandflies were collected using sticky traps. Each trap consists of 13 white sheets of paper $(20 \mathrm{~cm} \times 20 \mathrm{~cm})$ soaked in castor oil, yielding a total surface of $1 \mathrm{~m}^{2}$. The density is reported as the number of a sandfly species per $1 \mathrm{~m}^{2}$ of sticky traps [1]. Three $\mathrm{m}^{2}$ of sticky traps, corresponding to 3 replicates, were placed inside active rodent burrows from dusk to dawn at each of the four sites. Active rodent burrows are characterized by the presence of Chenopodiaceae fragments and feces at their entries [14]. Taking into account the number of sites $(n=4)$ and the number of rodent burrows per site $(n=39)$, the total number of trap nights was 468. Collected sandflies were identified individually at species level according to morphological characteristics [17]. Sandflies were then pooled based on collection date with a maximum of 30 unfed females per pool and stored at $-80^{\circ}$ until use. 


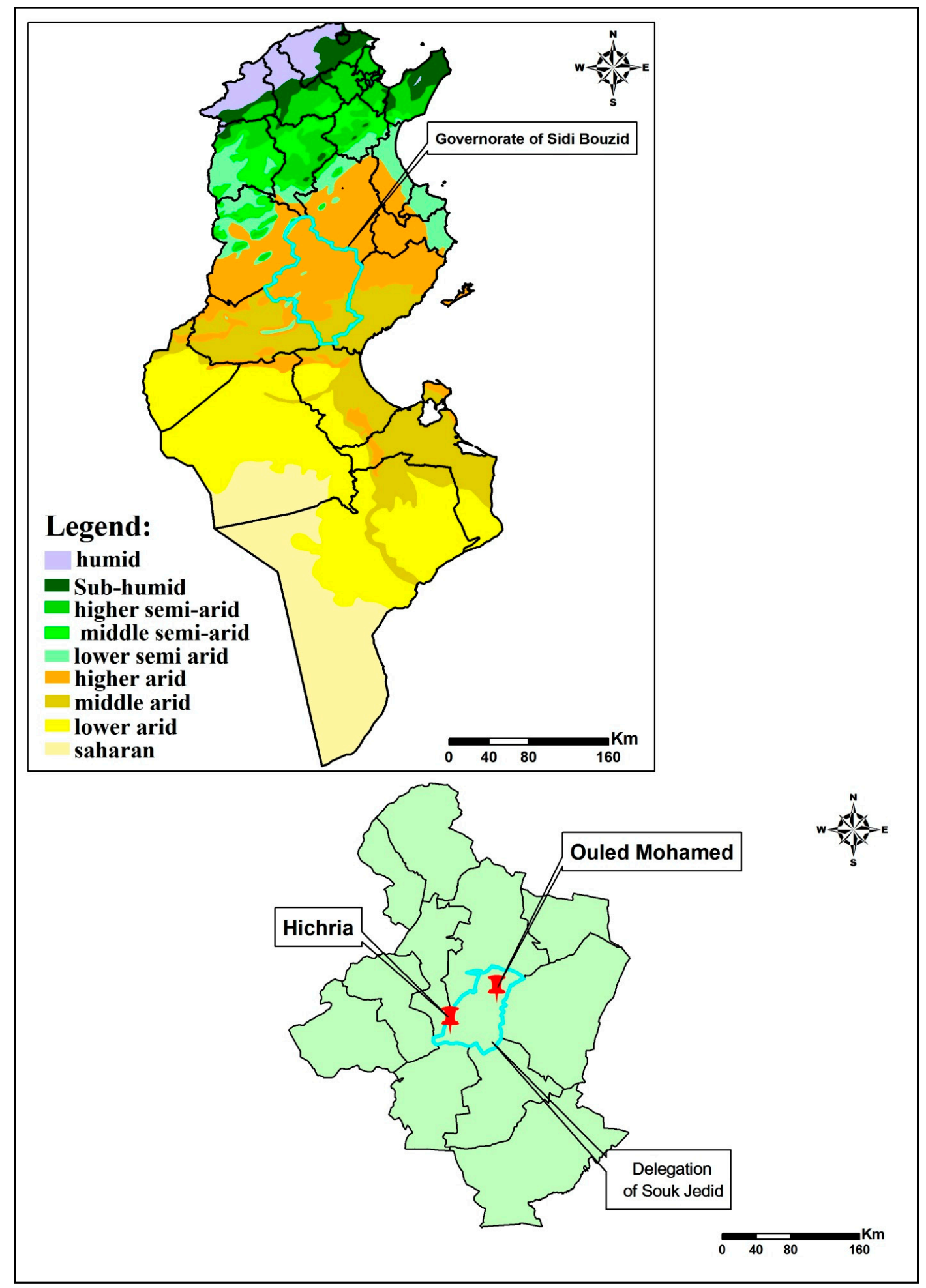

Figure 1. Bioclimatic map of Tunisia showing sampling sites in the governorate of Sidi Bouzid. 


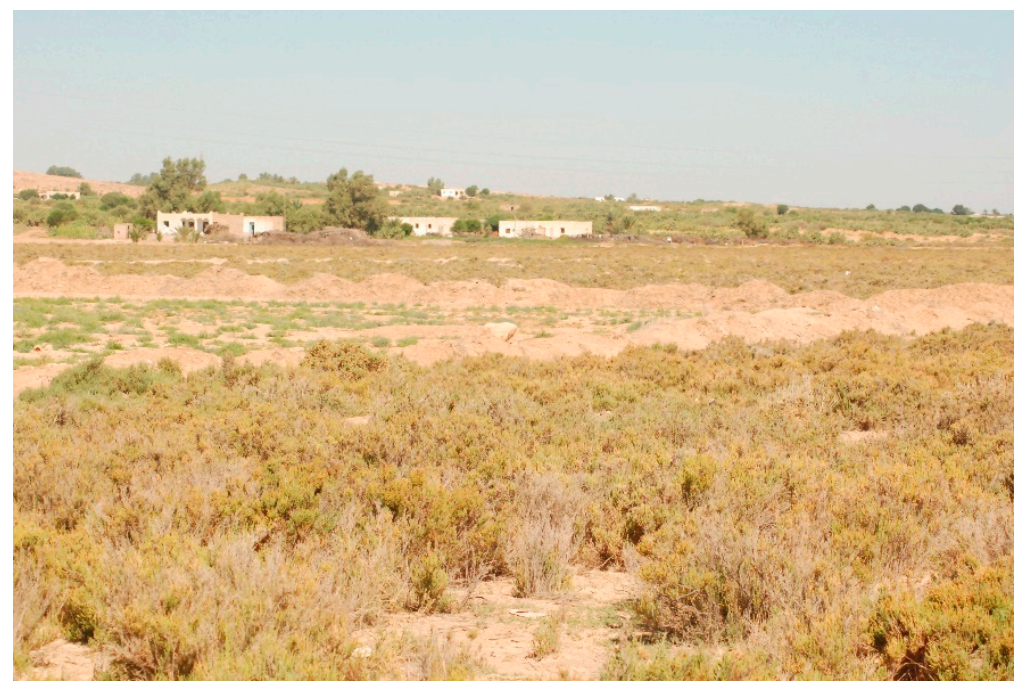

Figure 2. Chenopod fields surrounding villages.

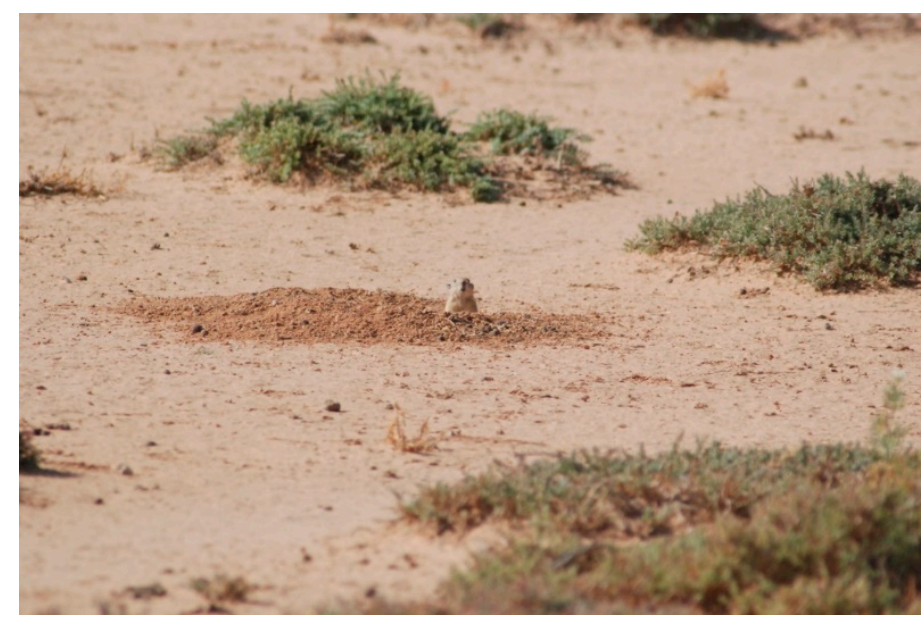

Figure 3. Psammomys obesus in its natural habitat (chenopod field; A).

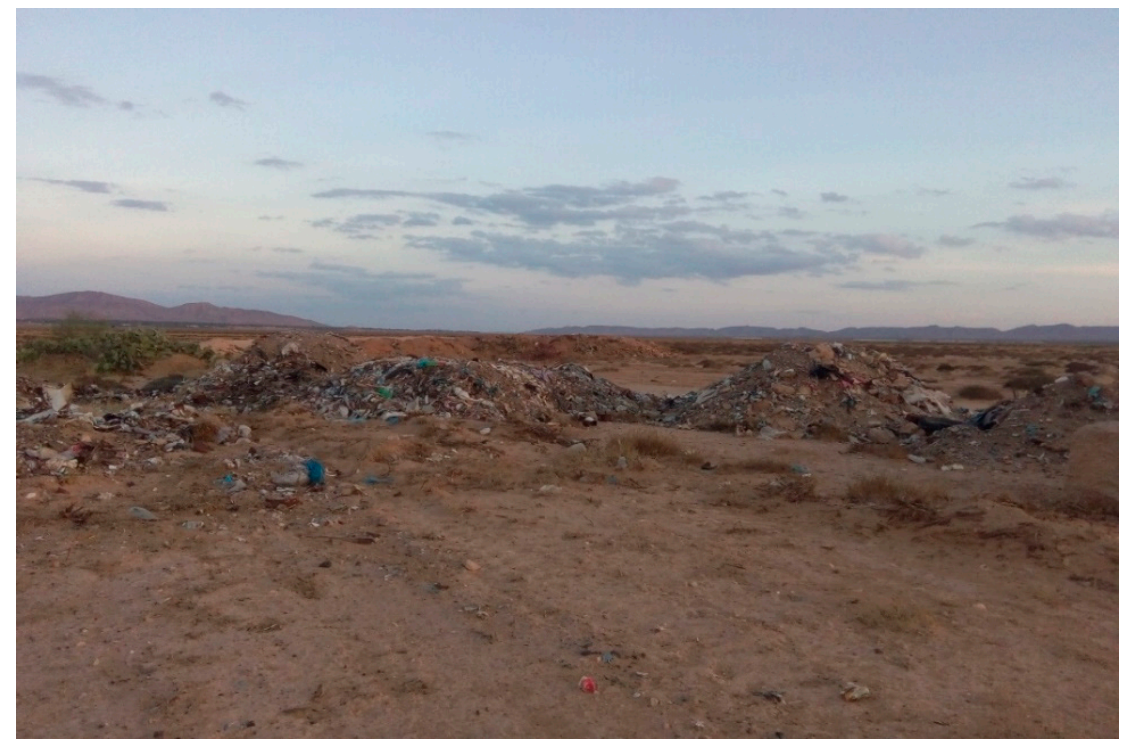

Figure 4. Dumpsites made of household waste adjacent to chenopod fields. 
Female sandflies in pools of up to a maximum of 30 specimens per pool were homogenized in $200 \mu \mathrm{L}$ of phosphate-buffered saline (PBS) solution through high-speed shaking using the automated Tissue Lyser LT (Qiagen, Germany) with glass beads. The mixture was clarified by centrifugation at $6000 \times g$ for 2 min for use in DNA extraction with a Qiagene DNA Mini Kit (Qiagen, Germany) according to the manufacturer's instructions. L. major, L. infantum and L. tropica DNA previously extracted from parasite cultures were used as positive controls. DNA extracted from sandfly pools was screened for the presence of Leishmania DNA (as a proxy for Leishmania infection) using a nested PCR-based schizodeme method targeting the partially conserved region of the kinetoplast minicircle DNA, as described previously [18]. The method enabled Leishmania species discrimination on the basis of PCR amplicon size, where L. tropica generated a 750-bp product, L. infantum produces a 680 -bp product, whereas the product size of L. major was $560 \mathrm{bps}$. For each DNA sample extracted from pools of sandflies, an initial amplification step was performed using the Taq DNA recombinant polymerase kit (Invitrogen) in a $50 \mu \mathrm{L}$ reaction containing $5 \mu \mathrm{L}$ 10X buffer, $3 \mu \mathrm{L} \mathrm{MgCl} 2(50 \mathrm{mM}), 2 \mu \mathrm{L}$ dNTP mix $(10 \mathrm{mM}), 1 \mu \mathrm{L}$ of each reverse and forward primer (CSB2xF/CSB1xR $(10 \mu \mathrm{M})), 0.5 \mu \mathrm{L}$ Taq and $10 \mu \mathrm{L}$ of total extracted DNA. The nested PCR was carried out in a $50 \mu \mathrm{L}$ reaction containing $3 \mu \mathrm{L}$ of the initial PCR and $47 \mu \mathrm{L}$ of a mixture containing $5 \mu \mathrm{L} 10 \mathrm{X}$ buffer, $3 \mu \mathrm{L} \mathrm{MgCl} 2(50 \mathrm{mM}), 2 \mu \mathrm{L} \mathrm{dNTP}$ mix $(10 \mathrm{mM}), 1 \mu \mathrm{L}$ of each reverse and forward internal primer $(13 \mathrm{Z} / \mathrm{LIR}(10 \mu \mathrm{M}))$ and $0.5 \mu \mathrm{L}$ of Taq DNA polymerase (Invitrogen). Optimized cycling conditions for the first and second PCR step were performed as follows: $94{ }^{\circ} \mathrm{C}$ for $5 \mathrm{~min}$ followed by 35 cycles, repeating denaturation at $94^{\circ} \mathrm{C}$ for $30 \mathrm{~s}$, annealing at $55^{\circ} \mathrm{C}$ for $60 \mathrm{~s}$ and elongation at $72{ }^{\circ} \mathrm{C}$ for $90 \mathrm{~s}$, and an extension step at $72{ }^{\circ} \mathrm{C}$ for $10 \mathrm{~min}$. Cross-contamination was monitored by negative controls for sample extraction and PCR solutions. Amplification products of the nested PCR were confirmed by electrophoresis in ethidium bromide-stained $2 \%$ agarose gel. Positive PCR product sizes were estimated according to $100 \mathrm{bp}$ molecular weight (Invitrogen) to identify sandfly-associated Leishmania species. In this study, the infection of P. papatasi by L. major is reported using the minimum infection rate (MIR) which is calculated: ([number of positive pools/total number of tested sandflies] $\times 100$ ) [19].

We conducted an overall analysis to evaluate whether densities of $P$. papatasi are higher in dumpsites compared to chenopod fields. The densities of sandflies and the MIRs were analyzed using a non-normal distribution approach. A Wilcoxon rank sum test was used to study the null hypothesis with no significant difference between chenopod fields and dumpsites in terms of sandfly densities and in term of MIRs. $p$ values were considered significant at 0.05. Statistics were assessed using R 3.6.0.

\section{Results}

A total of 666 and 528 sandflies were collected from Hichria and Ouled Mohamed during 2017, respectively. Morphological identification of sand files showed that P. papatasi was the most abundant species in Hichria and in Ouled Mohamed (Table 1). A total of 361 and 291 sandflies were collected from Hichria and Ouled Mohamed during 2018, respectively. Morphological identification of sand files showed that $P$. papatasi was the most abundant species in both villages (Table 1). Other sandflies were identified such as Phlebotomus perniciosus and Sergentomyia minuta, but their abundances are low compared to P. papatasi (Table 1).

In Hichria, the overall sandfly densities in the dumpsites and in the chenopod fields were $46.33 \pm 8.39$ and $10.10 \pm 1.22$, respectively. The overall density in the dumpsites is significantly higher compared to the density in the chenopod fields $(W=5, p$-value $=0.04113)$ (Figure 5). In Ouled Mohamed, the overall sandfly densities in the dumpsites and in the chenopod fields were $41.28 \pm 2.33$ and $12.14 \pm 1.18$, respectively. Similar to the village of Hichria, the overall density in the dumpsites is significantly higher compared to the density in the chenopod fields $(\mathrm{W}=0, p$-value $=0.002165)$ (Figure 6$)$. 
Table 1. Sandfly fauna collected in Hichria and in Ouled Mohamed in 2017 and 2018.

\begin{tabular}{|c|c|c|c|c|c|c|}
\hline \multirow{2}{*}{$\begin{array}{l}\text { Years } \\
\text { Sites }\end{array}$} & \multicolumn{3}{|c|}{2017} & \multicolumn{3}{|c|}{2018} \\
\hline & \multicolumn{2}{|c|}{ Hichria } & $\begin{array}{c}\text { Ouled } \\
\text { Mohamed }\end{array}$ & \multicolumn{2}{|c|}{ Hichria } & $\begin{array}{c}\text { Ouled } \\
\text { Mohamed }\end{array}$ \\
\hline $\begin{array}{c}\text { Total numbers } \\
\text { of sandflies }\end{array}$ & \multicolumn{2}{|c|}{666} & 528 & \multicolumn{2}{|c|}{361} & 291 \\
\hline Genus & \multicolumn{2}{|c|}{ Phlebotomus } & Phlebotomus & Phlebotomus & Segentomyia & Phlebotomus \\
\hline Species & papatasi & perniciosus & papatasi & papatasi & minuta & papatasi \\
\hline $\operatorname{Sex}(F / M)$ & $205 / 453$ & $3 / 5$ & $148 / 380$ & $72 / 285$ & $0 / 4$ & $108 / 183$ \\
\hline Abundance (\%) & 98.8 & 1.2 & 100 & 98.2 & 1.2 & 100 \\
\hline
\end{tabular}

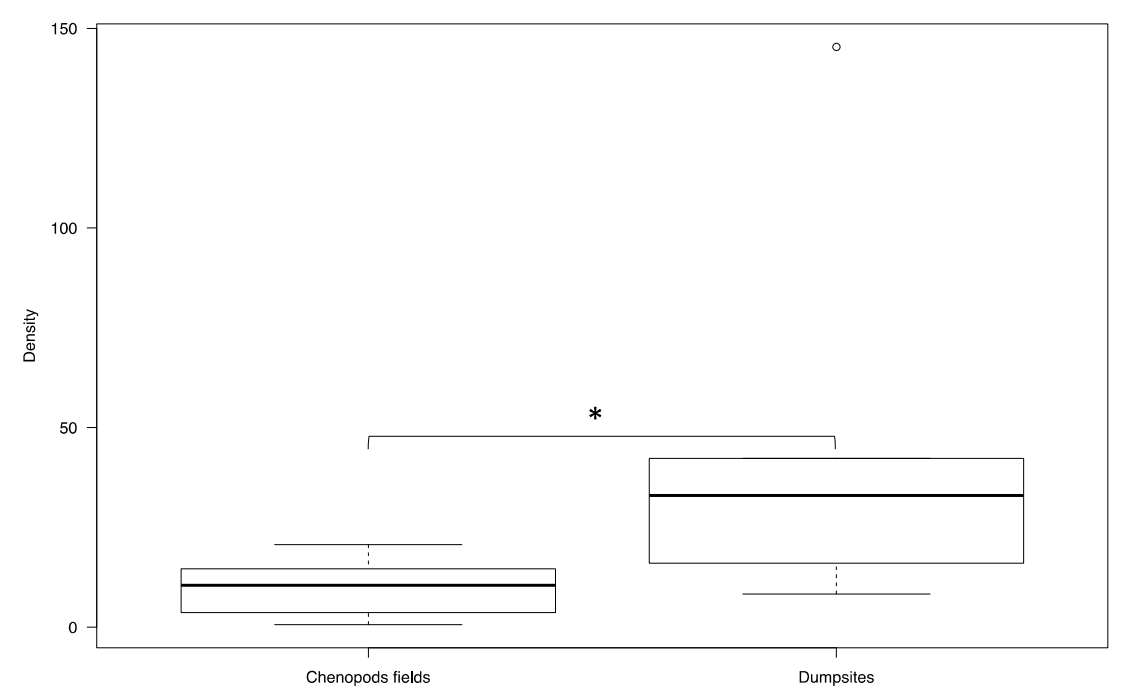

Figure 5. Overall densities of Phlebotomus papatasi in the chenopod fields and in the dumpsites adjacent to the village of Hichria. (The thick black line represents the median. Lower and upper lines represent the first and third quartile, respectively. Whiskers show the minimum and maximum values. Outliers are represented by circles. Significance: ${ }^{*}<0.05$.

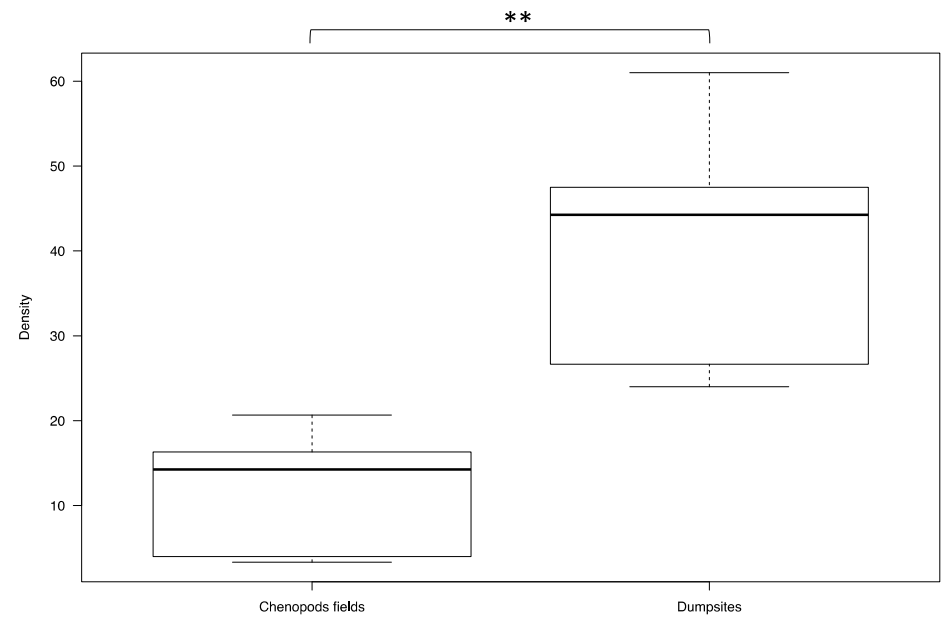

Figure 6. Overall densities of Phlebotomus papatasi in the chenopod fields and in the dumpsites adjacent to the village of Ouled Mohamed. (The thick black line represents the median. Lower and upper lines represent the first and third quartile, respectively. Whiskers show the minimum and maximum values. Significance: ${ }^{* *}<0.01$.) 
In 2017, a total of 177 and 29 P. papatasi females collected from the waste disposal site and from the chenopod fields surrounding the village of Hichria, respectively, were tested for Leishmania infection by nested PCR (Table 2). The MIRs in the waste disposal site and in the chenopod fields surrounding the village of Hichria were 2.25, and 3.44, respectively. A total of 125 and 22 P. papatasi females collected in 2017 from the waste disposal site and from the chenopod fields surrounding the village of Ouled Mouhamed, respectively, were tested for Leishmania infection by nested PCR (Table 2). The MIRs in the waste disposal site and in the chenopod fields surrounding the village of Ouled Mohamed were 2.44, and 4.54, respectively. Only L. major was detected in the studied areas according the PCR product size during the 2017 season.

Table 2. Minimum infection rates of Phlebotomus papatasi with Leishmania major in Hichria and in Ouled Mohamed.

\begin{tabular}{|c|c|c|c|c|c|c|c|}
\hline \multirow[t]{2}{*}{ Villages } & \multirow[t]{2}{*}{ Sites } & \multicolumn{2}{|c|}{$\begin{array}{c}\text { N. Pools/Total Number of } \\
\text { Females }\end{array}$} & \multicolumn{2}{|c|}{$\begin{array}{c}\text { N. Positive Pools/Total } \\
\text { Number of Females }\end{array}$} & \multicolumn{2}{|c|}{ Minimum Infection Rate } \\
\hline & & 2017 & 2018 & 2017 & 2018 & 2017 & 2018 \\
\hline \multirow{2}{*}{ Hichria } & Dumpsites & $7 / 177$ & $3 / 52$ & $4 / 177$ & $3 / 52$ & 2.25 & 5.76 \\
\hline & $\begin{array}{l}\text { Chenopod } \\
\text { fields }\end{array}$ & $1 / 29$ & $1 / 16$ & $1 / 29$ & $1 / 16$ & 3.44 & 6.25 \\
\hline \multirow{2}{*}{$\begin{array}{c}\text { Ouled } \\
\text { Mohamed }\end{array}$} & Dumpsites & $5 / 125$ & $5 / 90$ & $3 / 125$ & $4 / 90$ & 2.44 & 4.44 \\
\hline & $\begin{array}{l}\text { Chenopod } \\
\text { fields }\end{array}$ & $1 / 22$ & $1 / 18$ & $1 / 22$ & $1 / 18$ & 4.54 & 5.55 \\
\hline
\end{tabular}

In 2018, a total of 52 and 16 P. papatasi females from the waste disposal site and from the chenopod fields surrounding the village of Hichria, respectively, were tested for Leishmania infection by nested PCR. The MIRs in the waste disposal site and in the chenopod fields surrounding the village of Hichria were 5.76 and 6.25, respectively (Table 2). A total of 90 and 18 P. papatasi females from the waste disposal site and from the chenopod fields surrounding the village of Ouled Mohamed, respectively, were tested for Leishmania infection by nested PCR (Table 2). The MIRs in the waste disposal site and in the chenopod fields surrounding the village of Ouled Mohamed were 4.44 and 5.55, respectively (Table 2). Similar to the 2017 season, only L. major was detected in studied areas according the PCR product size during the 2018 season. Overall, the MIRs in the dumpsites and in the chenopod fields were $4.43 \pm 0.32$ and $4.24 \pm 0.22$, respectively. No significant difference was found between the MIRs in both sites ( $\mathrm{W}=7, p$-value $=0.8857$ ) (Figure 7).

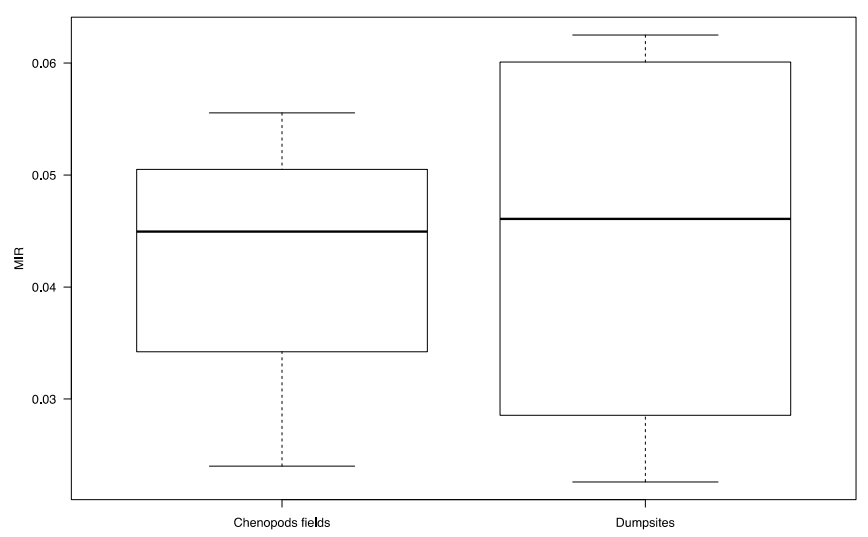

Figure 7. The minimum infection rates of P. papatasi with L. major in dumpsites $(n=4)$ and chenopod fields $(n=4)$. (The thick black line represents the median. Lower and upper lines represent the first and third quartile, respectively. Whiskers show the minimum and maximum values. 


\section{Discussion}

In ZCL endemic foci, waste sites rich in organic waste, rubber, plastic, animal dung, and earthen matter deposited illegally at the edge of villages and close to chenopod fields form dumpsites that attract rodents, particularly P. obesus. These dumpsites are of major interest in relation to $P$. obesus as they provide shelter from heavy rainfall and subsequent drowning, as well as proximity to chenopods, which represent their main food source (14). It is of major epidemiological importance to point out that these illegal waste sites are within $1 \mathrm{~km}$ of villages. Our entomological survey, performed over a two-year period, showed that illegal waste sites sustained a large population of P. papatasi. In these waste sites, active rodent burrows have moderate, stable temperatures, elevated humidity, and are rich in organic matter, which creates a suitable microclimate for the immature and adult stages of $P$. papatasi [10]. Adult P. papatasi females utilize P. obesus as their primary blood meal source, and the rodent feces, plant debris, and organic waste that accumulate in these burrows are the main food sources for sandfly larvae, and subsequently contribute significantly to sustaining a large population of P. papatasi, characterized by high densities. Therefore, a significantly higher density of P. papatasi in waste sites compared to natural biotopes is expected. This could be explained by the high abundance of P. obesus in the waste sites compared to the chenopod fields around villages [20]. This hypothesis deserves further investigation.

A high MIR in P. papatasi females with L. major was found in the waste sites. However, no significant difference was observed between the MIRs in the dumpsites and in the chenopod fields. A previous study performed by our group showed that the infection prevalence values for P. obesus infected with L. major in the same waste sites in Hichria and Ouled Mohamed were $33 \%$ and $60 \%$, respectively [15]. The infection prevalence of $P$. obesus with L. major captured from the chenopod fields in Ouled Mohamed was reportedly $41 \%$ [9]. Similar to the chenopod fields, P. obesus is the main source of infection of P. papatasi in the waste sites. Since the potential risk of direct transmission of infectious diseases by any kind of solid waste depends on the presence of an infectious agent, its viability in solid waste, and the presence of a susceptible host [21], our results provided strong evidence that illegal waste sites represent a high risk factor of ZCL for the surrounding communities.

It is of major epidemiological importance to point out that the governorate of Sidi Bouzid has the highest ZCL prevalence nationwide [2,22]. In endemic rural areas located in the center of the governorate of Sidi Bouzid, the annual average incidence rate was 502.9 cases per 100,000 inhabitants [22]. Ouled Mohamed has the highest annual incidence of ZCL, with 3822.8 cases per 100,000, followed by Hichria with 1660.4 cases per 100,000 inhabitants [22]. Considering that the flight range of P. papatasi is around $0.75 \mathrm{~km}$ [23], increases in the densities of P. papatasi in illegal waste sites located at the edge of villages expand the overlap of infected ZCL vectors with communities, leading to a high incidence of ZCL. This hypothesis is corroborated by the fact that the distance between the source of the epidemic and the dwellings with human cases in endemic areas of Central Tunisia required to reach an epidemic of ZCL was estimated at approximately $1 \mathrm{~km}$ [24]. Thus, illegal waste sites pose a high risk of spreading ZCL to neighboring home ranges. Due to the occupation of land near these dumpsites, at the edge of villages and close to chenopod fields, the natural habitat of $P$. obesus may have established a direct link between the sylvatic and peri-urban cycles of ZCL.

Several studies showed the impact of illegal waste sites on vector-borne diseases such as dengue [25], rodent-borne diseases such leptospirosis [26], toxoplasmosis [27], and zoonotic viruses [28]. However, few studies linking illegal waste and leishmaniasis have been performed. The risk of visceral leishmaniasis in South America increased with the absence of regular trash collection [29]. Phlebotomus argentipes, a vector of visceral leishmaniasis in the Indian subcontinent, breeds in the trash [30]. Our findings showed higher densities of $P$. papatasi in illegal waste sites compared to the natural environment. In addition, The MIRs observed in the natural sites and the dumpsites are similar. Thus, the results of our study provided strong evidence that illegal waste sites significantly increase 
the risk of transmission of ZCL. Therefore, improved waste management is essential in the prevention and the control of ZCL in endemic countries. Unsuitable waste management at the edge of villages located in ZCL endemic areas is providing ideal conditions for breeding and resting sites for $P$. papatasi populations and subsequently increasing the risk of ZCL. Similar to several neglected tropical diseases, such as trachoma, schistosomiasis, soil-transmitted helminthiasis, and Guinea worm, the prevention and control of ZCL also depend on the availability of improved water, sanitation, and hygiene (WASH) in ZCL endemic rural communities [31].

\section{Conclusions}

Based on our entomological findings, we concluded that waste management through the education of communities to resist trash accumulation at the vicinity of villages in order to reduce the risk of ZCL transmission should be included in an integrated vector management program.

Author Contributions: E.Z., I.C. designed the study. I.F., O.M., and W.F. collected and analyzed the data, S.Z. and A.B. performed the statistical analysis. S.C., M.A., K.D., M.D., and W.B. collected the data. E.Z. wrote the manuscript. All authors have read and agreed to the published version of the manuscript.

Funding: This study was funded in part through by US NIH R21 (5R21AI117107-02, PI: EZ).

Conflicts of Interest: The authors declare no conflict of interest.

\section{References}

1. Chelbi, I.; Derbali, M.; AL-Ahmadi, Z.; Zaafouri, B.; El Fahem, A.; Zhioua, E. Phenology of Phlebotomus papatasi (Diptera: Psychodidae) relative to the seasonal prevalence of zoonotic cutaneous leishmaniasis in Central Tunisia. J. Med. Entomol. 2007, 44, 385-388. [CrossRef] [PubMed]

2. Chelbi, I.; Kaabi, B.; Bejaoui, M.; Derbali, M.; Zhioua, E. Spatial Correlation between Phlebotomus papatasi Scopoli (Diptera: Psychodidae) and Incidence of Zoonotic Cutaneous Leishmaniasis in Tunisia. J. Med. Entomol. 2009, 46, 400-402. [CrossRef] [PubMed]

3. Ismail, R.B.; Gramiccia, M.; Gradoni, L.; Helal, H.; Rachid, M.B. Isolation of Leishmania major from Phlebotomus papatasi in Tunisia. Trans. R. Soc. Trop. Med. Hyg. 1987, 81, 749. [CrossRef]

4. Derbali, M.; Chelbi, I.; Ahmed, S.B.H.; Zhioua, E. Leishmania major Yakimoff et Schokhor, 1914 (Kinetoplastida: Trypanosomatidae) chez Meriones shawi Duvernoy, 1842 (Rodentia: Gerbillidae): Persistance de l'infection du mérion et de son infectivité pour le phlébotome vecteur Phlebotomus (Phlebotomus) papatasi Scopoli, 1786 (Diptera: Psychodidae). Bull. Société Pathol. Exot. 2012, 105, 399-402. [CrossRef]

5. Rioux, J.A.; Petter, F.; Zahaf, A.; Lanotte, G.; Houin, R.; Jarry, D.; Perieres, J.; Martini, A.; Sarhani, S. Isolement de Leishmania major Yakimoff et Schokhor, 1914 [Kinetoplastida-Trypanosomatidae] chez Meriones shawi (Duvernoy, 1842) [Rodentia-Gerbillidae] en Tunisie. Ann. Parasitol. Hum. Comparée 1986, 61, 139-145. [CrossRef]

6. Ismail, R.B.; Rachid, M.S.B.; Gardoni, L.; Gramiccia, M.; Bach-Hamba, D. La leishmaniose cutanée zoonotique en Tunisie; étude du réservoir dans le foyer de Douara. Ann. Soc. Belge Méd. Trop. 1987, 67, 335-343.

7. Rioux, J.A.; Ashford, R.W.; Khiami, A. Ecoepidemiology of leishmaniases in Syria. 3. Leishmania major infection in Psammomys obesus provides clues to life history of the rodent and possible control measures. Ann. Parasitol. Hum. Comparée 1992, 67, 163-165. [CrossRef]

8. Fichet-Calvet, E.; Jomâa, I.; Ismail, R.B.; Ashford, R.W. Leishmania major infection in the fat sand rat Psammomys obesus in Tunisia: Interaction of host and parasite populations. Ann. Trop. Med. Parasitol. 2003, 97, 593-603. [CrossRef]

9. Ghawar, W.; Toumi, A.; Snoussi, M.-A.; Chlif, S.; Zaatour, A.; Boukthir, A.; Hamida, N.B.H.; Chemkhi, J.; Diouani, M.F.; Ben-Salah, A. Leishmania major Infection Among Psammomys Obesus and Meriones Shawi: Reservoirs of Zoonotic Cutaneous Leishmaniasis in Sidi Bouzid (Central Tunisia). Vector Borne Zoonotic Dis. 2011, 11, 1561-1568. [CrossRef]

10. Derbali, M.; Polyakova, L.; Boujaâma, A.; Burruss, D.; Cherni, S.; Barhoumi, W.; Chelbi, I.; Poché, R.; Zhioua, E. Laboratory and field evaluation of rodent bait treated with fipronil for feed through and systemic control of Phlebotomus papatasi. Acta Trop. 2014, 135, 27-32. [CrossRef]

11. Chahed, M.K.; Bellali, H.; Ben Jemaa, S.; Bellaj, T. Psychological and Psychosocial Consequences of Zoonotic Cutaneous Leishmaniasis among Women in Tunisia: Preliminary Findings from an Exploratory Study. PLoS Negl. Trop. Dis. 2016, 10, e0005090. [CrossRef] [PubMed]

12. Ammar, R.B.; Ismail, R.B.; Helal, H.; Bach-Hamba, D.; Chaouch, A.; Bouden, L.; Hanachi, A.; Zemzari, A.; Rachid, M.S.B. Un nouveau foyer de leishmaniose cutanée de type rural dans la region de Sidi Saad. Bull. Soc. Fr. Parasitol. 1984, 2, 9-12. 
13. Salah, A.B.; Kamarianakis, Y.; Chlif, S.; Alaya, N.B.; Prastacos, P.; Salah, A.B.; Alaya, N.B. Zoonotic cutaneous leishmaniasis in central Tunisia: Spatio temporal dynamics. Int. J. Epidemiol. 2007, 36, 991-1000. [CrossRef] [PubMed]

14. Fichet-Calvet, E.; Jomâa, I.; Zaafouri, B.; Asford, R.W.; Ismail, R.B.; Delattre, P. The spatio-temporal distribution of a rodent reservoir host of cutaneous leishmaniais. J. Appl. Ecol. 2000, 37, 603-615. [CrossRef]

15. Cherni, S. The Impact of Household Wastes on the Pullulating of Rodent Reservoir Host of Leishmania major in Central Tunisia. Master's Thesis, University of Tunis El Manar, Tunis, Tunisia, 2017.

16. Müller, G.C.; Kravchenko, V.D.; Rybalov, L.; Schlein, Y. Characteristics of resting and breeding habitats of adult sand flies in the Judean Desert. J. Vector Ecol. 2011, 36 (Suppl. 1), S195-S205. [CrossRef]

17. Croset, H.; Rioux, J.-A.; Maistre, M.; Bayar, N. Les Phlébotomes de Tunisie (Diptera, Phlebotomidae). Mise au point systématique, chorologique et éthologique. Ann. Parasitol. Hum. Comparée 1978, 53, 711-749. [CrossRef]

18. Noyes, H.A.; Reyburn, H.; Bailey, J.W.; Smith, D. A Nested-PCR-Based Schizodeme Method for Identifying Leishmania Kinetoplast Minicircle Classes Directly from Clinical Samples and Its Application to the Study of the Epidemiology of Leishmania tropica in Pakistan. J. Clin. Microbiol. 1998, 36, 2877-2881. [CrossRef]

19. Barhoumi, W.; Fares, W.; Cherni, S.; Derbali, M.; Dachraoui, K.; Chelbi, I.; Ramalho-Ortigão, M.; Beier, J.C.; Zhioua, E. Changes of Sand Fly Populations and Leishmania infantum Infection Rates in an Irrigated Village Located in Arid Central Tunisia. Int. J. Environ. Res. Public Health 2016, 13, 329. [CrossRef]

20. Fichet-Calvet, E.; Jomâa, I.; Giraudoux, P.; Asford, R.W. Estimation of sand rat abundance by using surface indices. Acta. Theriol. 1999, 44, 353-362. [CrossRef]

21. Krystosik, A.; Njoroge, G.; Odhiambo, L.; Forsyth, J.E.; Mutuku, F.; LaBeaud, A.D. Solid Wastes Provide Breeding Sites, Burrows, and Food for Biological Disease Vectors, and Urban Zoonotic Reservoirs: A Call to Action for Solutions-Based Research. Front. Public Health 2020, 7, 405. [CrossRef]

22. Bellali, H.; Hchaichi, A.; Harizi, C.; Mrabet, A.; Chahed, M.K. Comparison between active surveillance and passive detection of zoonotic cutaneous leishmaniasis in endemic rural areas in Central Tunisia, 2009 to 2014. Asian Pac. J. Trop. Dis. 2015, 5, 515-519. [CrossRef]

23. Orshan, L.; Elbaz, S.; Ben-Ari, Y.; Akad, F.; Afik, O.; Ben-Avi, I.; Dias, D.; Ish-Shalom, D.; Studentsky, L.; Zonstein, I. Distribution and Dispersal of Phlebotomus papatasi (Diptera: Psychodidae) in a Zoonotic Cutaneous Leishmaniasis Focus, the Northern Negev, Israel. PLoS Negl. Trop. Dis. 2016, 10, e0004819. [CrossRef] [PubMed]

24. Mbarki, L.; Salah, A.B.; Chlif, S.; Chahed, M.K.; Balma, A.; Chemem, N.; Garraoui, A.; Ismail, R.B. Monitoring zoonotic cutaneous leishmaniasis with GIS. In GIS for Health and Environment; Savigny, D., Wijeyaratne, P., Eds.; IDCR-Ottawa Publications: Ottawa, ON, Canada, 1995; pp. 115-125.

25. Banerjee, S.; Aditya, G.; Saha, G.K. Household Wastes as Larval Habitats of Dengue Vectors: Comparison between Urban and Rural Areas of Kolkata, India. PLoS ONE 2015, 10, e0138082. [CrossRef] [PubMed]

26. Munoz-Zanzi, C.; Mason, M.; Encina, C.; Gonzalez, M.; Berg, S. Household Characteristics Associated with Rodent Presence and Leptospira Infection in Rural and Urban Communities from Southern Chile. Am. J. Trop. Med. Hyg. 2014, 90, 497-506. [CrossRef]

27. Ivovic, V.; Potusek, S.; Buzan, E. Prevalence and genotype identification of Toxoplasma gondii in suburban rodents collected at waste disposal sites. Parasite 2019, 26, 27. [CrossRef]

28. Duh, D.; Hasic, S.; Buzan, E. The impact of illegal waste sites on a transmission of zoonotic viruses. Virol. J. 2017, 14, 134. [CrossRef]

29. Costa, C.H.N.; Werneck, G.L.; Rodrigues, L.; Santos, M.V.; Araújo, I.B.; Moura, L.S.; Moreira, S.; Gomes, R.B.B.; Lima, S.S Household structure and urban services: Neglected targets in the control of visceral leishmaniasis. Ann. Trop. Med. Parasitol. 2005, 99, 229-236. [CrossRef]

30. Singh, S.P.; Mishra, R.N.; Reddy, D.C.S.; Sundar, S. Knowledge, attitude, and practices related to kala-azar in a rural area of bihar state, india. Am. J. Trop. Med. Hyg. 2006, 75, 505-508. [CrossRef]

31. Freeman, M.C.; Ogden, S.; Jacobson, J.; Abbott, D.; Addiss, D.G.; Amnie, A.G.; Beckwith, C.; Cairncross, S.; Callejas, R.; Jr, J.M.C.; et al. Integration of Water, Sanitation, and Hygiene for the Prevention and Control of Neglected Tropical Diseases: A Rationale for Inter-Sectoral Collaboration. PLoS Negl. Trop. Dis. 2013, 7, e2439. [CrossRef] 